\title{
UMA ANÁLISE DO CONTO/TESTEMUNHO NADA DE NOVO NA FRENTE OCIDENTAL, DE LYGIA FAGUNDES TELLES
}

Suênio Campos de Lucena Universidade do Estado da Bahia

RESUMO

Esse artigo analisa "Nada de Novo na Frente Ocidental", narrativa que encerra o livro Invenção e memória (2000), da escritora Lygia Fagundes Telles. A partir do hibridismo que conjuga fatos reais e ficção, a autora realiza um conto/testemunho que inclui a abordagem em torno da lembrança e do esquecimento. Assim, esta análise destaca tanto a questão das tensões entre verdade e criação literária, quanto a relação da autora/protagonista, ao relembrar o passado com saudosismo e nostalgia, no caso, a São Paulo dos anos 1950, quando foi legionária. Um episódio marcante norteará um corte e tentativa de esquecimento a todo custo: a morte do pai, fazendo com que ela tente bloquear e sobrepor tristes recordações. Tendo por base a Psicanálise, a discussão deste conto possibilita reflexões sobre a lembrança, o esquecimento e, também, sobre a passagem do tempo e a morte.

PALAVRAS-CHAVE: Memória; Lygia; passado; esquecimento; testemunho. 


\section{Invenção e memória: ficção e realidade na obra de Lygia Fagundes Telles}

Lygia Fagundes Telles [1923 - ] tem se firmado como expressiva ficcionista brasileira, cuja obra, até o momento, já foi traduzida para cerca de quinze países, tendo diversos contos e romances premiados, além de adaptados para a televisão, cinema e teatro. Dos seus livros, apenas os mais recentes, Invenção e memória (2000), Durante aquele estranho chá (2002) e Conspiração de Nuvens (2007), têm caráter confessional. Neles há contos/testemunhos com flagrante inspiração memorialista ou autobiográfica. E, embora declaradamente não-ficcionais, em todos a autora realiza um depoimento do vivido sempre permeado por elementos ficcionais. A esses livros devemos acrescentar ainda um anterior, A disciplina do amor (1980), escrito em forma de fragmentos, que mescla ficção e testemunho. Em princípio, esses títulos até podem parecer exceções em sua produção, mas uma análise mais atenta revelará o quanto eles se articulam com grande parte da escrita da autora, porque, conforme veremos, a lembrança e o esquecimento têm importante papel constitutivo em sua narrativa e, destacados, podem ampliar ainda mais a compreensão de sua obra. Por isso, decidimos abordar as questões da lembrança e do esquecimento também como tema e procedimento estilístico decisivos para o entendimento da narrativa lygiana. Assim, ao desenvolvermos a leitura que abrange esta questão em sua narrativa, vamos perceber que a memória, o esquecimento e o passado são explorados não apenas em seus escritos considerados memorialistas, mas também em grande parte da sua ficção ${ }^{1}$, isso porque a autora opera com um embaralhamento de discursos e de experiências, tornando desnecessário verificar onde começa a ficção e onde acaba a (sua) reelaboração do vivido.

O livro Invenção e memória (2000) reúne quinze textos curtos em que a autora aborda a infância passada nas cidades de Assis, Descalvado e Sertãozinho (em "Que se chama solidão" e "Cinema gato preto"); a juventude na capital (nas narrativas "Dança com anjo", "Heffman" e "Nada de novo na frente ocidental"); além da maturidade em "Dia de dizer não" e "Rua Sabará, 400", entremeadas por histórias fictícias, como "O Menino e o velho" e "História de passarinho", entre outras. São textos de ficção que se misturam a textos de memória a fim de descreverem histórias que giram em torno da vida literária da geração da autora, que 
gravitou em torno da região central paulistana durante o pós-guerra, quando a capital paulista passa por intenso processo modernizante.

A despeito de citar datas, locais e nomes próprios, qualquer análise deve abordar esse livro como busca e tentativa de exercitar narrativas hibridas entre registro pessoal e literário, o que distancia a autora da verdade do narrado, registro importante para atentarmos que nele não se deve tentar separar escritos reais dos fictícios, mas percebê-los como narrativas em forma de crônicas, fragmentos e contos. Daí, chamarmos mesmo aqueles que tratam de lembranças de esboços de memória, uma vez que, embora relatem episódios reais, reflitam sobre questões brasileiras, descrevam encontros com escritores e registrem a efervescência literária da São Paulo dos anos 1940-50, os textos são produzidos com elementos ficcionais, num sentido ao que Antonio Candido se refere aos livros Infância e Memórias do cárcere, de Graciliano Ramos, cuja: "fatura convém tanto à exposição da verdade quanto da vida imaginária; nele as pessoas parecem personagens e o escritor se aproxima delas por meio da interpretação literária, situando-as como criações... toda biografia de artista contém maior ou menor dose de romance" (CANDIDO, 1992, p. 50).

Anunciado como o primeiro livro de não-ficção de Lygia Fagundes Telles, Invenção e memória, entretanto, segue premissa literária, com lembranças associadas à natureza (quintal, água correndo debaixo das jabuticabeiras, verdes canudos de mamoeiro, latidos etc.) e a hábitos característicos de fazendas e cidades do interior, vistos como elementos que integram o paraíso perdido da narradora. A intenção é deliberadamente embaralhar discursos, vasos comunicantes, junção que mescla autor, narrador e personagem, conforme descreve o teórico Philippe Lejeune $(1975)^{2}$.

De qualquer forma, nos parece inapropriado discutir a questão verdade/ficção se tomarmos a premissa da literatura como representação, já que, mesmo em seus testemunhos, a autora recorre a ambivalências e dubiedades, de modo que os textos de Invenção e memória devem ser lidos como testemunhos, mas também como contos, pois: "se por um lado se apresentam como ficções, por outro lado, não enjeitam esse lado vivido, a consagração de uma experiência e de uma carreira extraliterária que tem sido a do escritor e é documentada pela sua existência civil" (SEIXO, 1998, p. 474). 


\section{Conto/testemunho Nada de novo na frente ocidental}

"Nada de novo na frente ocidental", último texto de Invenção e memória, se passa no período da juventude da escritora na cidade de São Paulo ${ }^{3}$ durante a $2^{\mathrm{a}}$. Guerra Mundial, quando reside com a mãe num “pequeno apartamento no primeiro andar de um edifício na rua Sete de Abril, ao lado da Praça da República" (TELLES, 2000, p. 118). O relato se centra na participação em defesa da pátria, episódio relembrado ("ah, o susto que minha mãe levou quando me viu aparecer fardada"; TELLES, 2000, p. 119) no momento em que sua mãe se arruma "para tomar o ônibus na rodoviária, ia cumprir uma promessa na cidade de Aparecida, era uma ardorosa devota de Nossa Senhora" (TELLES, 2000, p. 117).

A narradora relembra um dia na vida da legionária de 22 anos enquanto se prepara para encontrar-se com um colega poeta. Por esse período, a maior preocupação de sua mãe é "encaminhá-la", pois casar uma filha é garantir o futuro dela: "Veja, filha, você já é escritora, estuda numa escola só de homens e agora virou também soldado?! Achei graça porque adivinhei o que ela pensou em seguida e não disse, agora é que vai ser mesmo difícil casar" (TELLES, 2000, p. 119).

Relatar o próprio passado não é algo objetivo, ainda mais quando narrado por uma ficcionista. Esta concepção seguida à risca por Lygia Fagundes Telles só reforça a ideia de que ela escreve sobre sua vida sem deixar de criar, ou seja, recriar-se, uma das ideias referenciais de Lejeune a fim de conceituar o texto autobiográfico. Para ele, é necessário aproximar a identidade do autor com a do narrador e da personagem para se configurar o gênero: Os fatos podem ser modificados em sua "verdade", mas o sujeito da narrativa deve coincidir com a individualidade do autor. Apesar disso, Lejeune considera questionável a classificação, uma vez que uma ficção autobiográfica pode parecer-nos exata, enquanto uma autobiografia pode ser inexata, tratando-se de modalidade textual que conjuga história individual com história inventada; vida recriada ${ }^{4}$.

Segundo o teórico, é preciso que as figuras de autor e narrador se confundam e que o texto seja um depoimento sobre sua vida, além de o narrador ser também personagem central, como é o caso de "Nada de novo...". Tal mescla firma um texto híbrido entre relato e ficção. O pacto que Lejeune menciona se refere a um eu textual que muitas vezes se apresenta distinto do eu da experiência vivida ${ }^{5}$. De todo modo, o leitor não 
parece interessado em verificar a veracidade e autenticidade das informações relatadas, ao contrário. Parece desejar estabelecer esse pacto justamente para possibilitar que o seu leitor leia Invenção e memória como misto de verdade e ficção. Ou seja, o leitor dos livros da autora não irá diferenciar seus livros, uma vez que ele não deve cobrar uma eventual intenção de verdade por parte da autora/narradora, pois a sua perspectiva é ler ficção, encarando memória como algo refutável, moldada no presente e elaborada com elementos de que o escritor dispunha quando escreveu.

Segundo Pedro de Souza, essa prática tenta não apenas esgarçar e explorar os limites discursivos e literários, mas, sobretudo, busca realizar a afirmação de uma memória cultural coletiva paulista(na) no sentido de: "reconstrução de ambientes literários da vida intelectual do escritor, sua linhagem e a sua inserção na poética e no pensamento cultural da época" (SOUZA, 2000, p. 45), algo que Lygia Fagundes Telles realiza nesse livro ao se inserir no rol dos acontecimentos históricos e culturais da época, ou seja, trata-se de memória individual e também coletiva, descrita em meio a episódios reais, mas narrados com elementos e recursos ficcionais.

Assim é a estrutura da narrativa "Nada de novo...", conto/testemunho que não se propõe ser registro histórico ${ }^{6}$. Este é, afinal, o pacto de que fala Lejeune, cujos limites entre fato e invenção são tênues e igualmente difíceis de serem estabelecidos, uma vez que o testemunho se mescla à ficção, mas também é baseado em fatos reais.

\section{A morte do pai e o desejo de esquecer o passado}

Um tema irá servir como mote da narrativa "Nada de Novo na Frente Ocidental": a morte do pai. As lembranças da mãe se despedindo e seus preparativos para o encontro de logo mais serão bruscamente interrompidos por este fato triste, anunciado através de um telefonema: "enquanto a minha mãe viajava... uma voz de homem me anunciava pelo telefone que meu pai tinha morrido subitamente num quarto de hotel onde estava hospedado na pequena cidade de Jacareí” (TELLES, 2000, p. 123). A partir daí, a narradora vai procurar sobrepor diversas lembranças à lembrança do telefonema; tentativa de apagá-la da memória, como se, ao fazê-lo, conseguisse evitar a morte do pai. A ideia é deslocar e substituir a triste lembrança por outras, como a viagem da mãe e o encontro de logo mais, que, entretanto, não deve ocorrer. Ao esquecer, ela pode restabelecer certa ordem na vida cotidiana da jovem estudante que reside com a mãe, reordenando suas existências, ameaçadas repentinamente pelo anúncio de morte. 
É frequente o desejo de algumas personagens de Lygia Fagundes Telles ansiarem por certa ordem que elas encontram em lembranças idealizadas do passado. Ao recordar, optam por esquecer fatos considerados tristes ${ }^{7}$, realizando filtragens, cortes e acréscimos. No caso de "Nada de novo...", a intenção é exatamente esta: No presente, quando relembra e descreve o ocorrido, a narradora deseja "esquecer" o telefonema em busca da preservação da tranquilidade, para ela ameaçada àquela época pelo anúncio da morte do pai. Talvez por isso a partir do momento em que toma conhecimento do fato triste, a narrativa vá acompanhar o descontrole, tornando-se fragmentada. Com isso, fracassa a intenção de "esquecer" o telefonema e de congelar o tempo até o momento em que foi informada, instante em que sua vida e a de sua mãe transcorriam serenamente.

Esquecer em "Nada de novo na frente ocidental" segue intenção de apagar acontecimentos considerados inconvenientes, inadequados, ruins, negativos ${ }^{8}$. Mesmo assim, perdura a aflição porque embora deseje esquecer, esperançosa com o futuro, há certa agonia devido à consciência de que o gesto vá fracassar. A narradora sabe que toda filtragem é movediça, uma vez que avançar no tempo é lembrar a morte do pai. E mesmo esquecer não parece ser algo redentor, pois não trará o pai de volta nem conseguirá congelar o tempo. O resultado é a reação melancólica, pois sabe que vai lembrar, algo que provoca dor, pois ela não consegue esquecer.

Muitas das personagens de Lygia Fagundes Telles temem a passagem do tempo, daí uma saída constantemente tentada é relembrar fatos positivos e idealizados. Aí se inclui a protagonista de "Nada de novo...", que deseja manter e prolongar a sensação de um dia feliz, tranquilo: "por que avançar no tempo?” (TELLES, 2000, p. 123) se pergunta, preferindo relembrar momentos anteriores à notícia, quando preparava um lanche:

Mas espera um pouco, estou me precipitando, por que avançar no tempo? Ainda não tinha acontecido nada, era manhã quando minha mãe se preparava para a viagem, ia ver minha madrinha e eu ia ver o meu poeta, espera!... Deixa eu viver plenamente aquele instante enquanto comia o pão com queijo quente e já estendia a mão para o bule de chocolate, espera! Espera. A hora ainda era a hora do sonho" [grifos nossos] (TELLES, 2000, p. 123).

A narradora se vigia para não avançar no tempo, uma vez que prefere relembrar a "hora do sonho", aquela repleta de expectativas, em que seu pai estava vivo e fatos positivos poderão ocorrer. Porém, a narrativa 
assume tom dramático porque tem consciência da "impossibilidade de fazer parar a roda do tempo", como afirma Leonardo Monteiro (1980). Daí o relato angustiado e o artifício de só lembrar "a hora do sonho", destacando uma vida sem sobressaltos, cotidiano inalterado que deve ser repisado a fim de evitar sofrimento, pois uma das características da autora é, justamente, a aproximação entre lembrança e dor, como se esquecer fosse índice de felicidade, aqui apenas vislumbrado, não concretizado e ameaçado pela lembrança indesejável.

O recurso encontrado é tentar esquecer o telefonema, apagar a morte do pai e imaginar-se cuidando de um soldado na $2^{\mathrm{a}}$. Guerra Mundial, uma lembrança que age como desejo de sobreposição e também a fim de reforçar o auto-perfil de jovem ingênua e altruísta, enfermeira dedicada na cidade italiana de Nápoles:

enquanto assistia às aulas no curso de enfermagem, era com esse uniforme sem nódoas que me imaginava, cuidando do jovem soldado com suas bandagens (ferimentos leves) que eu removia com mãos levíssimas... Nápoles. Fui convocada juntamente com a nova leva dos nossos pracinhas... A cantina sem os violinos mas com a guitarra e a voz tão poderosa cantando. Cantando. Então o homem disse com voz grave, uma notícia triste, acontece que o seu pai... ele não era o seu pai? Espera um pouco, pelo amor de Deus, espera! Acontece que ainda é manhã e estou tão contente porque me vejo na cantina e dizendo ao soldado pálido que não falo italiano mas entendo tudo, minha avó era italiana... (TELLES, 2000, p. 124).

A descrição de um cotidiano sem sobressaltos se soma à voz imaginária de um cantor italiano, mas essa suposta voz não é suficiente para abafar sua triste lembrança. $\mathrm{O}$ artifício fracassa porque a todo momento o devaneio é interrompido pela lembrança da morte paterna. Assim, não consegue congelar o tempo nem esquecer. Ao perceber a impotência, a última tentativa é incitá-lo a evitar a morte, mesmo sabendo que ele já está morto: "Pai, depressa, mude de lugar como fazia quando queria mudar de assunto, vá para os pés da cama se ela estiver na cabeceira, saia do quarto e vá para a rua! Abro a porta e respiro. É cedo, não avance no tempo" (TELLES, 2000, p. 125).

O adiamento da lembrança atua como deslocamento por outras, bem mais amenas e felizes, análogo à necessidade de casar, à despedida da mãe, ao desejo de ser escritora, à atuação como legionária e ao possível encontro de logo mais. Todo o texto é construído em sobreposições (lembranças positivas versus negativas) e subterfúgios, sempre na expectativa 
de apagar aquilo que a desagrada.

A narradora reage tentando esquecer o fato trágico porque a lembrança ameaça a sua vida tranquila e confortável, até o momento em que fica sabendo do triste fato: "acomodei-me confortavelmente na poltrona diante do telefone, assim podia ouvir melhor quando ele ligasse para confirmar o encontro. Estendi as pernas até o almofadão e pensei como era maravilhoso ficar assim disponível, sonhando e esperando por alguma coisa que vai acontecer" (TELLES, 2000, p. 125). O desejo é adiar a lembrança da morte e sonhar com algo positivo, fato que pode conseguir negar a lembrança indesejável. Diante da morte a ser encarada sobrepõe lembrança encobridora, forma de manter a tranquilidade cotidiana.

Aqui se pode recorrer aos estudos de Sigmund Freud, particularmente o seu escrito "Lembranças encobridoras", no momento em que a narradora tenta relembrar apenas de fatos positivos. $\mathrm{O}$ encontro com um poeta, o pão com queijo quente e o encontro imaginário com um soldado numa cantina em Nápoles são tentativas de encobrir, de sobrepor lembranças negativas insistentes e de evitar o luto e a melancolia ${ }^{9}$ que viriam em seguida. Para Freud: "há numerosos tipos possíveis de casos em que um conteúdo psíquico aparece em lugar de outro" (FREUD, 2006, p. 274). Ele chama esses artifícios da memória de deslocamentos, indicando que existem duas forças psíquicas que estabelecem um conflito: "Uma dessas forças encara a importância da experiência como um motivo para procurar lembrá-la, enquanto a outra - uma resistência - tenta impedir que se manifeste" (FREUD, 1987, p. 274). Em seguida, afirma que "prevalece a resistência" (FREUD, 2006, p. 274), ou seja, uma lembrança trivial que pode substituir outra, negativa. Esforço, entretanto, que muitas vezes fracassa, como é o caso de "Nada de novo...", em que a narradora desloca a morte do pai para pormenores que, para ela, são significantes porque tencionam encobrir lembranças desagradáveis, daí o desejo de $p a-$ rar o tempo até o momento em que toma conhecimento da morte do pai.

Em seu ensaio "Luto e melancolia", de 1915, incluído no livro $A$ história do movimento psicanalítico, artigos sobre metapsicologia e outros trabalhos, Sigmund Freud enfatiza a reação de incredulidade, negação e tristeza profunda, isto é, ferida narcísica que não tem prazo específico para ser vencida e que os indivíduos têm diante da perda de entes queridos. Não se tratando de algo patológico ou que requeira tratamento clínico, o luto é marcado pela: "perda de interesse pelo mundo externo na medida em que este não evoca esse alguém - ... perda da capacidade de 
adotar um novo objeto de amor (o que significaria substituí-lo)" (FREUD, 2006, p. 250). Para ele, trata-se de processo que é quase um jogo provocado pela memória, não sendo inteiramente intencional, pois em larga medida é defesa psíquica contra o luto, a dor, o sofrimento. Muitas vezes resulta desse conflito a sensação de melancolia, vazio e desencanto, como nesse caso em que a narradora de "Nada de novo na frente ocidental" demonstra grande ansiedade por não conseguir reter o irrelevante nem suprimir a morte do pai das suas lembranças.

No texto em pauta, a intenção é evitar inclusive lembrar do que se seguiu à morte paterna, forma de escapar dos pormenores posteriores ao telefonema. Com isso, a ficção invade o registro do testemunho - a morte do pai de Lygia -, e atua como representação que assume importância decisiva para a escritora não ter de relatar o vivido conforme exatamente aconteceu, mas permeá-lo de elementos fictícios. Através da literatura, ela não se obriga a narrar a verdade, mas recontá-la, reconstruí-la com elementos do presente.

No caso de "Nada de novo..." tem-se o relato da escritora madura relembrando um eu passado, o de jovem reprimida, com dificuldades financeiras, pressionada pela mãe para casar-se virgem e que fica sabendo da morte do pai. No entanto, a despeito das adversidades, o testemunho, filtrado pelo presente, é marcado por certo otimismo, esperança, romantismo e idealismo, mesmo diante de uma realidade determinada por privações e limitações, impostas durante a Guerra Mundial. Com isso, segue-se a premissa de que recordar não é reviver uma experiência, mas reconstruí-la com elementos do presente a partir dos materiais à disposição, ou seja, lembranças e esquecimentos são filtrados, jamais narrados na totalidade. Talvez por isso, ao relatar o cotidiano de quando fazia o curso de Direito na Faculdade do Largo de São Francisco e atuava como legionária em "duros treinamentos no Vale do Anhangabaú" (TELLES, 2000, p. 119), ressaltando a pressão para casar-se virgem, a repressão da época em torno do gênero feminino, insiste a abordagem romântica, altruísta e de harmonia familiar - essa é a configuração de jovem que Lygia Fagundes Telles deseja registrar.

$\mathrm{O}$ relato em tom de desabafo feito à mãe e recriado pela escritora por exemplo trata-se de testemunho desalentador da passagem do tempo, da destruição e esquecimento inexoráveis dos indivíduos e das coisas, mas não só. Tenta registrar que sua juventude, mesmo ficcionalizada, não deve(ria) ser apagada, esquecida: "vai passar, mãe. Tudo isso vai passar. 
Vai passar esta guerra e vai passar a outra que vier em seguida... Você mesma, mãe, e também eu, vamos todos passar sem deixar memória como esse camundongo... vai passar, repeti em silêncio enquanto acenava" (TELLES, 2000, p. 122). Ao narrar esse tempo, a escritora realça e traz à tona valores como virgindade, crença religiosa, fé em Deus e altruísmo, compondo um auto-retrato idealizado em meados do século $\mathrm{XX}$, cuja lembrança da morte do pai atua como elemento antagônico e ameaça esse perfil, daí o desejo de esquecê-la ou deslocá-la por outra.

A intenção é enfatizar a imagem de jovem corajosa, engajada, que passou por restrições ("quem não tinha geladeira devia conservar a manteiga fresca dentro de uma vasilha de água diariamente renovada"; TELLES, 2000, p. 117), mas, mesmo assim, lutou pela pátria ao se engajar e ter senso coletivo; imagem construida de jovem idealista, uma quase heroína que se vê como enfermeira salvando um soldado no campo de batalha, resoluta em manter "a paz" ao lado da mãe com quem vive num modesto apartamento próximo à Praça da República.

Período de transição e de limitações e incertezas, cujos valores e marcas são relatados no sentido de se distanciar dos costumes do presente, associado à violência, ao consumismo, à exacerbação do sexo etc. Mantém o espirito de conservação e o receio da ruptura - imagem que Lygia Fagundes Telles pretende fixar no momento em que escreve, sendo dispensável e secundária se verdadeira ou não, isto é, se a escritora realiza invenção ou memória, uma vez que é exatamente nesse movimento pendular que se move o seu conto/testemunho.

Ao escrever, a ficcionista procura "reencontrar" a juventude via literatura, mas ela já não está mais aí a não ser na tentativa de não ter a lembrança dessa imagem sobreposta pelas lembranças da despedida do pai. No entanto, ainda que a lembrança da jovem insista, há um tom triste porque ela é mera recordação, resiste somente na memória. Ao relatá-la, a narradora busca evitar que caia no esquecimento: "Viver plenamente aquele instante" (TELLES, 2000, p. 123) é solicitar que não esqueçam o tempo da escritora quando jovem, época em que acreditava no "sonho" e que seu pai estava vivo, um tempo cujas possibilidades futuras estavam abertas - é essa jovem que Lygia Fagundes Telles deseja firmar, mas cuja (re) construção é ameaçada pela morte paterna.

A intenção diz respeito ao desejo de a narradora no presente, quando reflete sobre o vivido e o narra deixando evidente o registro do passado com olhos de hoje. Assim, tem-se o relato um tanto idealista da 
jovem que tenta vencer adversidades em prol de uma causa específica, a literatura; ser escritora é o projeto que começa a ser esboçado. O texto está permeado de acréscimos, cortes e seleções a fim de se reelaborar como personagem, ou seja, o passado é contado com o filtro do presente. Segundo tal raciocínio, "Nada de novo na Frente Ocidental” é: "operação transformadora, tradutora, criadora, portanto, em que o original, já reduzido a apenas um traço no momento de sua inscrição, será menos resgatado que reinventado, menos ponto de chegada que ponto de partida para a construção de uma outra estória" (BRANCO, 2003, p. 39).

Ao escrever e rememorar um triste episódio do passado, a escritora Lygia Fagundes Telles procurou (re)contar a sua vida destacando o fato de ter sido uma jovem engajada. A menção da farda demonstra a imagem de garota responsável, séria, patriótica - "visto a minha farda e pronto, vou defender a pátria em perigo!" (TELLES, 2000, p. 119) -, eis o retrato atual pretendido sobre o que ela foi e vivenciou em seu passado, num período de quando foi jovem e frequentou a Confeitaria Vienense, um tempo que não volta mais. Essas são algumas marcas do conto/testemunho "Nada de Novo na Frente Ocidental" e, de resto, que ilustra os processos, mecanismos e estratégias de criação de uma das nossas maiores escritoras ao se referir a algo que lhe aconteceu, narrado embaralhando discursos e vozes. 


\section{A CRITIC OF THE SHORT STORY/TESTIMONY NADA DE NOVO NA FRENTE OCIDENTAL, LYGIA FAGUN- DES TELLES'S}

\section{ABSTRACT}

This article analyzes "Nada de Novo na Frente Ocidental", narrative that concludes the book Invenção e memória (2000), writer's Lygia Fagundes Telles. From the hybridism that conjugates real facts and fiction, the author realizes a tale / testimony that includes the approach around the memory and the forgetfulness. Thus, this analysis highlights both the question of the tensions between truth and literary creation, as well as the relation of the author / protagonist, when recalling the past with nostalgia, in this case, the São Paulo of the 1950s, when she was legionary. One striking episode will guide a cut and attempt of oblivion at all costs: the death of the father, causing her to try to block sad memories. Based on Psychoanalysis, the discussion of this tale makes possible reflections on remembrance, forgetfulness and also on the passage of time and death.

KEY-WORDS: Memory; Lygia Fagundes Telles; past; forgetfulness; testimony.

\section{NOTAS}

${ }^{1}$ Segundo Lívia de Freitas Reis: "os testemunhos também podem ser ficcionalizados; o que nada diminui o seu caráter de depoimento. As autobiografias por sua preocupação com o original, com a literariedade, também não raro são ficcionalizadas e, tanto em uma como em outra, podemos detectar técnicas e procedimentos estéticos e literários. Ambos assimilam a ficção (o romance) e o não ficcional (a história)... os testemunhos podem ser lidos como documentos etnográficos, antropológicos, sociológicos, até psicológicos, mas o leitor sempre os lerá como ficção, pois é este o código que ele domina e empresta sentido ao que lê. O leitor lê o testemunho e a autobiografia como ficção, e não lhe importa a verdade contida no relato. Desta maneira o que ele lê é literatura" (REIS, 1996, p. 178). Da mesma 
forma que Lívia Freitas, Luana Soares de Souza observa: “Ao observar a emergência do Eu ao nível do discurso, a crítica deixou de procurar na autobiografia a representação mais ou menos fiel de uma história pessoal, e prefere entendê-la como uma recriação em que se fundem memória e imaginação" (SOUZA, 1997, p. 130).

${ }^{2}$ Segundo Lejeune trata-se de: "narrativa retrospectiva em prosa que uma pessoa real faz de sua própria vida, quando põe em relevo, principalmente, suas experiências individuais, em especial a história de sua personalidade" (LEJEUNE, 1975, p. 119). Ou seja, trata-se de discurso que pretende ser verdadeiro e arte: "A autobiografia literária coloca-se na fronteira entre o relato verídico, referencial dos fatos acontecidos e a ficção, construção literária marcada por recursos estilísticos e estéticos... O paradoxo da autobiografia literária, seu essencial jogo duplo, é o de pretender ser, ao mesmo tempo, um discurso verídico e uma obra de arte, um sistema de tensão entre a transparência referencial e a pesquisa estética" (LEJEUNE, 1975, p. 209).

${ }^{3}$ Era nas Ruas Marconi e Barão de Itapetininga que ficavam a Livraria Jaraguá e a Confeitaria Vienense, onde os transeuntes tomavam chá às cinco da tarde $\mathrm{e}$ percorriam lojas e cafés, praticando o chamado footing. Dentre os frequentadores, Oswald de Andrade e Mário de Andrade, Antônio de Alcântara Machado, Alfredo Mesquita (dono da Livraria Jaraguá e criador da EAD, Escola de Arte Dramática), além de Décio de Almeida Prado, Antonio Candido de Mello e Souza e Paulo Emilio Salles Gomes (com quem Lygia se casaria), respectivamente atuando como críticos de teatro, literatura e cinema. Mais dados sobre o grupo ver o livro Destinos mistos - Os críticos do grupo Clima em São Paulo (1940/1968), de Heloísa Pontes.

${ }^{4}$ Conforme Lucia Castello Branco: "A tentativa de garantir corporeidade ao sujeito parece ser uma das preocupações fundamentais da narrativa memorialista. Situando-se como um eu 'real', que apenas momentaneamente recua da esfera do vivido, do 'lá fora' do mundo, para o interior do livro de memória, o sujeito, na solidão de quem se dirige a um $t u$ silencioso, desenha uma forma, assume uma função, expressa afetos e temores, na ilusão de, pela exibição reiterada de sua cena textual, adquirir existência" (BRANCO, 2003, p. 45).

${ }^{5}$ Segundo Carlos Riter: "Lygia... se metamorfoseia em outra, a fim de depor suas experiências, que, em virtude de estabelecerem um tempo narrativo que fica entre o atual e o passado, ressurgem contaminadas pelas sensações e emoções de um eu que não é mais o que viveu, mas o que recorda o vivido" (RITER, 2004, p. 194). Em A traição de Penélope, Lucia Castello Branco afirma: "O que sustenta o texto de memória é o mesmo que sustenta o texto de ficção: é preciso que algo 
de curioso, de atraente, de romanesco, se passe por ali. Não é à-toa, portanto, que as narrativas memorialistas são, de uma maneira ou de outra, sempre pontuadas pelo sentimento - ou pela promessa - de que aquele relato de vida se assemelha a um relato ficcional... Há aqui, no mínimo, um entrecruzamento de intenções: aquele mesmo relato que quer se fazer passar por verdadeiro... constrói-se a partir de elementos e de uma estrutura que se caracterizam como romanescos, como ficcionais" (BRANCO, 2003, p. 138).

${ }^{6}$ Ecléa Bosi relativiza o aspecto rígido até mesmo do discurso da História, também a mercê de versões e impressões subjetivas, dada à parcialidade das interpretações, discurso afeito a subjetividades e revisões: "O caráter livre, espontâneo, quase onírico da memória, é... excepcional. Na maior parte das vezes, lembrar não é reviver, mas refazer, reconstruir, repensar, com imagens e ideias de hoje, as experiências do passado” (BOSI, 1994, p. 55).

${ }^{7}$ Como analisa Jorge de Sá: “esquecer, para Lygia, não é apagar da lembrança, qualquer vestígio do acontecido. Esquecer, para ela e seus personagens, é filtrar os fatos, apagando os limites padronizados, afastando os detritos que possam impedir uma visão maior, deixando apenas os aspectos que fazem parte mesmo da condição humana e que torna possível compreender a própria humanidade. Esquecer, portanto, é filtragem... limpeza" (SÁ, 1981, p. 78). Mesmo raciocínio segue Leonardo Monteiro: “As personagens de Lygia vivem imersas na temporalidade. Elas não se livram da memória, do passado, das coisas antigas" (MONTEIRO, 1980, p. 103).

${ }^{8}$ No livro O conto brasileiro contemporâneo, Alfredo Bosi afirma: “há... a relação dramática com o passado, reino da posse e da perda. O convívio da consciência com a memória tem produzido um intimismo de situações novas, algumas ousadas e desafiadoras. Recuperar a imagem do que já foi, mas que ficou para sempre, é o esforço bem logrado da prosa ardente de Lygia Fagundes Telles” (BOSI, 1986, p. 10). Conforme Roberta Hernandes Alves: "Essa parece uma lição que é passada principalmente pelas personagens... de Lygia: é preciso conhecer o tempo, aproveitá-lo" (ALVES, 1998, p. 119). Como exemplo, eis um trecho de As meninas: "Tinha um relógio grande assim na torre e eu queria me agarrar nos ponteiros, segurar as horas, por que é que o tempo não parava um pouco? Queria ficar ali lá dependurado, segurando o tempo" (TELLES, 1973, p. 77).

${ }^{9}$ Freud verifica a melancolia como um longo luto, não necessariamente patológico, mas falta narcísica acometida pela diminuição do ego, baixa auto-estima com prolongamento saudosista. Ele foi dos primeiros a aproximar melancolia ao luto à nostalgia no sentido de não apenas conceituá-la, mas também clinicá-la, tratando-a separadamente da depressão. 


\section{REFERÊNCIAS}

AGUIAR, Joaquim Alves de. Espaços da memória. São Paulo: Edusp, 1998.

ALVES, Roberta Hernandes. Inocência e experiência: os ritos de passagem em Lygia Fagundes Telles. Dissertação (Mestrado em Literatura Brasileira). Faculdade de Filosofia, Letras e Ciências Humanas, Universidade de São Paulo. São Paulo, 1998.

BERGSON, Henri. Matéria e memória. São Paulo: Martins Fontes, 1999.

Memória e vida. São Paulo: Martins Fontes, 2006.

BOSI, Alfredo. Céu, inferno. São Paulo: Duas Cidades/34, 2004.

. O conto brasileiro contemporâneo. São Paulo: Cultrix, 1986.

BOSI, Ecléa. Memória e sociedade: lembranças de velhos. São Paulo: Companhia das Letras, 1994.

BRANCO, Lucia Castello. A traição de Penélope. São Paulo: Annablume, 2003. CANDIDO, Antonio. A educação pela noite e outros ensaios. São Paulo: Ática, 2003.

. Ficção e confissão. São Paulo: Editora 34, 1992.

CARDOSO, Lúcio. Crônica da casa assassinada. Rio de Janeiro: Civilização Brasileira, 1999.

COELHO, Nelly Novaes. A literatura feminina no Brasil contemporâneo. São Paulo: Siciliano, 1993.

FREUD, Sigmund. A interpretação dos sonhos. Rio de Janeiro: Imago, 1991.

. A história do movimento psicanalítico, artigos sobre metapsicologia e outros trabalhos. Rio de Janeiro: Imago, 2006.

1986.

Conferências introdutórias sobre psicanálise. Rio de Janeiro: Imago,

LEJEUNE, Philippe. Le pacte autobiographique. Paris: Éditions du Seuil, 1975. 2003.

El pacto autobiográfico y otros estudios. Madri: Megazul-endymion,

LUCENA, Suênio Campos de. 21 escritores brasileiros. São Paulo: Escrituras, 2001.

MENDES, Murilo. A idade do serrote. Rio de Janeiro: Record, 2003.

MENESES, Adélia Bezerra de. Do poder da palavra: ensaios de literatura e psicanálise. São Paulo: Duas Cidades, 1995. 
MENDES, Murilo. A idade do serrote. Rio de Janeiro: Record, 2003.

MENESES, Adélia Bezerra de. Do poder da palavra: ensaios de literatura e psicanálise. São Paulo: Duas Cidades, 1995.

MIRANDA, Wander Melo. Corpos escritos. São Paulo: Editora da UFMG/ EDUSP, 1992.

MONTEIRO, Leonardo. Literatura comentada: Lygia Fagundes Telles. São Paulo: Abril Cultural, 1980.

PEDRA, Mabel Knust. O círculo de giz: A família burguesa patriarcal em Lygia Fagundes Telles. Dissertação (Mestrado em Literatura Brasileira). Universidade Federal Fluminense. Niterói, 2005.

PONTES, Heloísa. Destinos mistos - Os críticos do grupo Clima em São Paulo (1940/1968). São Paulo: Companhia das Letras, 1998.

REIS, Lívia de Freitas. Autobiografia, testemunho e ficção: Uma relação delicada. GT “A mulher na literatura”. n. 6. Natal: UFRN, 1996.

RITER, José Carlos Dussarrat. A dor do passar: a cerimônia ficcional de Lygia Fagundes Telles. Tese (Doutorado em Literatura Brasileira). Instituto de Letras, Universidade Federal do Rio Grande do Sul. Porto Alegre, 2004.

SÁ, Jorge de. A indisciplina do real nos contos de Lygia Fagundes Telles. Boletim bibliográfico Biblioteca Mário de Andrade. v. 42, n. 4, out./dez. 1981.

SEIXO, Maria Alzira. Os romances de Antonio Lobo Antunes. Lisboa: Dom Quixote, 1998.

SOUZA, Pedro de. O esquecimento como condição da memória: A identidade em desabamento no ato de dizer. In: CAMPOS, Maria do Carmo; INDURSKY, Freda. Discurso, memória, identidade. Rio de Janeiro: Sagra Luzzato, 2000.

TELLES, Lygia Fagundes. A disciplina do amor. 9a . ed. Rio de Janeiro: Rocco, 1998.

. A noite escura e mais eu. $4^{\text {a }}$. ed. Rio de Janeiro: Rocco, 1998.

. Durante aquele estranho chá. Rio de Janeiro: Rocco, 2002.

. Invenção e memória. Rio de Janeiro: Rocco, 2000.

Recebido:17/01/2018

Aceito: 07/06/2018 